\title{
Penerapan Teknologi Augmented Reality Sebagai Model Media Edukasi Kesehatan Gigi Bagi Anak
}

\author{
Tonny Hidayat \\ Teknik Informatika STMIK AMIKOM Yogyakarta \\ E-mail: tonny_hank@amikom.ac.id
}

\begin{abstract}
Abstrak
Augmented Reality adalah sebuah teknologi yang relatif baru dan masih dikembangkan sampai saat ini. Konsepnya adalah menggabungkan dimensi dunia nyata dengan dimensi 'dunia nyata' yang termediasi, atau dunia virtual, untuk menciptakan kesan bahwa dimensi dunia nyata kita diperkaya dengan objek maya tiga dimensi. Hal ini dilakukan dengan cara 'menggambar' objek tiga dimensi pada marker, yakni sebuah 'pola' dalam bingkai segi empat yang bersifat unik dan dapat dikenali oleh aplikasinya. Aplikasi yang bersangkutan menerima input berupa video stream, yang berarti menggunakan input berupa citraan dari perangkat keras yang berfungsi menangkap gambar, biasanya sebuah webcam. Karena berupa video stream, artinya gambaran yang ditangkap sebagai input akan berubah-ubah, dan program harus dapat tetap mengenali marker meskipun berubah posisi dan orientasi relatif terhadap perangkat input. Pengenalan terhadap posisi dan pergerakan ini adalah salah satu konsep Teknologi Informasi yang bernama Computer Vision, dan digunakan untuk mendeteksi pola pergerakan relatif objek terhadap kamera.

Pendidikan terhadap anak harus dilakukan sedini mungkin terutama dalam hal kesehatan. Seiring dengan berkembangnya pemahaman masyarakat tentang pentingnya kesehatan gigi, banyak pihak yang telah memberikan informasi terkait kesehatan gigi di berbagai media. Tidak hanya orang dewasa yang menjadi sasaran akan tetapi juga mulai dari anak-anak sudah dikenalkan dengan pengetahuan tersebut. Karena dibutuhkan media penyampaian untuk anak maka banyak bermunculan media edukasi yang diharapkan bisamendidik anak dengan berbagai macam cara..

Pemanfaatan Augmented Realitysebagai alat untuk mengedukasi anak, ini akan memberikan pandangan baru terhadap media edukasi yang ada pada saat ini, bukan hanya menggunakan objek secara nyata tapi juga bisa digunakan objek berbentuk virtual dalam penyampaian informasi. Nilai tambah dari media ini adalah mempermudah penyampaian dan membuat informasi semakin menarik terutama bagi anak.
\end{abstract}

Kata Kunci - Augmented Reality, Edukasi, Kesehatan, Gigi

\begin{abstract}
Augmented Reality is a technology that is relatively new and still being developed today. The concept is to combine real-world dimensions to the dimensions of the 'real world' are mediated, or the virtual world, to create the impression that the dimensions of the real world we are enriched by virtual three-dimensional objects. This is done by 'drawing' a three-dimensional object on the marker, which is a 'pattern' in a rectangular frame that is unique and can be recognized by the application. Pertinent application accepts input in the form of a video stream, which means using the input in the form of images of the hardware image capture function, typically a webcam. Because the form of a video stream, meaning that as the input image captured will vary, and programs must be able to recognize the markers remained unchanged despite the position and orientation relative to the input device. Introduction to the position and movement is one of the Information Technology concept called Computer Vision, and is used to detect object movement patterns relative to the camera.
\end{abstract}


Education of children should be done as early as possible, especially in terms of health. Along with the development of public understanding about the importance of dental health, many people who have provided information related to dental health in a variety of media. Not only adults who were targeted but also start from the children has been introduced with such knowledge. Because it takes delivery of media for children then many emerging medium of education is expected to educate children with a variety of ways.

Utilization of Augmented Reality as a tool to educate the child, this will provide a new perspective on media education that existed at this time, instead of just using the real object but also can be used in the form of a virtual object in the delivery of information. The added value of this medium is to facilitate the delivery and make the information more interesting, especially for children.

Keywords - Augmented Reality, Education, Health, Dental

\section{PENDAHULUAN}

Teknologi informasi dan komunikasi yang berkembang begitu cepat mempengaruhi berbagai media yang sudah ada. Hal itu mendorong manusia untuk semakin kreatif dalam mengelola ilmu pengetahuan sehingga mampu merubah pola pikir manusia untuk dapat berfikir secara efektif dan efisien agar tidak tertinggal dalam perkembangan di dunia teknologi informasi dan komunikasi. Dalam perkembangan teknologi informasi dan komunikasi saat ini banyak melibatkan bidang multimedia karena efektif untuk menyampaikan informasi.

Teknologi di bidang multimedia yang sedang berkembang saat ini adalah Augmented Reality atau yang lebih dikenal dengan Realitas tertambah dalam bahasa Indonesia. Augmented Reality adalah teknologi yang menggabungkan benda maya dua dimensi dan ataupun tiga dimensi ke dalam sebuah lingkungan nyata tiga dimensi lalu memproyeksikan benda-benda maya tersebut dalam waktu nyata. Bisa diartikan juga bahwa Augmented Reality yang disingkat dengan AR adalah perwujudan dari benda di dunia maya ke dalam dunia nyata baik dalam dua dimensi atau tiga dimensi. AR pada saat ini mengalami perkembangan yang pesat dan telah menyentuh berbagai kehidupan salah satunya dalam dunia pendidikan.

Salah satu pembahasan dalam bidang pendidikan khususnya untuk anak-anak adalah bagaimana cara penyampaian materi untuk kesehatan gigi agar lebih menarik dengan menggunakan sebuah media. Media yang dimaksudkan untuk mempermudah penyampaian harus selalu berkembang agar anak-anak tidak bosan. Maka dengan penambahan teknologi AR yang ada akan mengenalkan teknologi tersebut kepada anak-anak sebagai wawasan bagi mereka dalam perkembangan teknologi. Selama ini penyampaian materi hanya menggunakan gambar, boneka atau video yang sudah biasa dilihat oleh anak-anak. Media yang digunakan dapat ditemukan di berbagai tempat sehingga mengurangi antusias anak-anak dalam memperhatikan.

Dengan adanya teknologi AR ini akan membantu menarik perhatian anak-anak karena dapat mempresentasikan secara virtual tiga dimensi dan real time sacara interaktif mengenai materi kesehatan gigi yang disampaikan sehingga anak-anak dapat lebih paham dan mengerti tentang materi yang ditampilkan. Penggunaan teknologi AR dalam media edukasi diharapkan dapat lebih menarik perhatian anak-anak dan menjadikan edukasi sebagai hal yang menarik untuk diikuti.

Banyak yang bisa dibangun menggunakan teknologi AR, dengan perangkat keras kamera atau webcam yang digunakan untuk menangkap objek gambar yang telah didesain kemudian gambar akan diterjemahkan oleh aplikasi yang dikenalkan dengan sebuah penanda atau dikenal dengan nama marker yang kemudian akan kembali menampilkan gambar beserta obyek yang telah dipasang dengan marker sebelumnya. Sehingga obyek nyata akan menyatu dengan obyek maya dalam tampilan akhir pada aplikasi. Berdasarkan uraian diatas, maka dapat dirumuskan sebuah permasalahan yaitu Bagaimana membuat buku edukasi menggunakan Augmented Reality berbasis 3D sebagai media penyampaian materi tentang kesehatan gigi untuk anak-anak. 
Suatu penelitian memerlukan adanya batasan masalah agar penelitian lebih terarah dan memudahkan dalam pembahasan, sehingga tujuan penelitian dapat dicapai sesuai kebutuhan.

Adapun beberapa batasan yang digunakan dalam penelitian adalah sebagai berikut.

1. Media edukasi kesehatan gigi dibuat untuk anak-anak berusia 4-7 tahun yang meliputi gigi seri, gigi taring dan gigi geraham.

2. Augmented Reality yang dibahas adalah menggunakan software ARToolKit. Penulis hanya mengaplikasikan software yang sudah ada dan tidak menjelaskan atau mengembangkan script (kode- kode pemograman) software ARToolKit.

3. Buku media edukasi kesehatan gigi ini membahas tentang bagaimana cara menyikat gigi yang benar untuk menjaga kesehatan gigi.

Pada penelitian ini yang akan dijadikan sebagai objek penelitian adalah jenis-jenis gigi yang terdapat pada mulut yaitu[1].

1. Gigi Seri adalah gigi yang memiliki satu akar, berada pada bagian depan, bentuknya tegak dengan tepi yang tajam seperti sekop atau tatah yang berfungsi untuk memotong dan mengerat makanan atau benda lainnya.

2. Gigi Taring adalah gigi yang memiliki satu akar, bentuknya tinggi dan runcing, memiliki fungsi untuk menyobek dan menarik makanan atau benda lainnya.

3. Gigi Geraham adalah gigi yang memiliki tiga akar, bentuknya lebih rendah dan lebih rata dengan benjolan-benjolan kecil yang berfungsi untuk menggilas, melumat serta mengunyah makanan atau benda lainnya.

Augmented Reality adalah penggabungan antara objek virtual dengan objek nyata. Sebagai contoh adalah saat pembawa acara televisi membawakan berita, ada animasi atau objek virtual yang ikut bersamanya, jadi seolah-olah dia berada di dalam dunia virtual tersebut, padahal sebenarnya itu adalah teknik penggabungan antara dunia virtual dengan dunia nyata yang dinamakan dengan Augmented Reality.

Augmented Reality adalah teknologi yang memungkinkan pandangan dari dunia nyata fisik yang ditambah kenyataan dengan citra yang dihasilkan virtual 3D, terdapat Virtual Reality sistem dimana dunia nyata yang menyatu dengan lingkungan virtual sehingga peneliti dari Amerika Serikat dan Jepang telah mengambil posisi terdepan dalam teknologi ini sejak 1990an[2].

Banyak bidang yang menerapkan teknologi AR salah satunya adalah di bidang pendidikan dan kesehatan. Dalam dunia pendidikan, AR digunakan untuk media presentasi. Augmented Reality memungkinkan pendengar untuk secara interaktif melihat bentuk objek 3D secara real time, apalagi jika pendengar tidak dapat melihat langsung benda atau objek yang dimaksud. Benda-benda maya menampilkan informasi yang tidak dapat diterima oleh pengguna dengan inderanya sendiri. Hal ini membuat Augmented Reality sesuai sebagai alat untuk membantu persepsi dan interaksi penggunanya dengan dunia nyata. Dengan adanya teknologi Augmented Reality ini akan sangat bermanfaat dan lebih menarik bagi dunia pendidikan dalam mempresentasikan secara virtual 3D objek edukasi, sehingga diharapkan pendengar dapat lebih paham dan mengerti tentang ilmu yang disampaikan. 


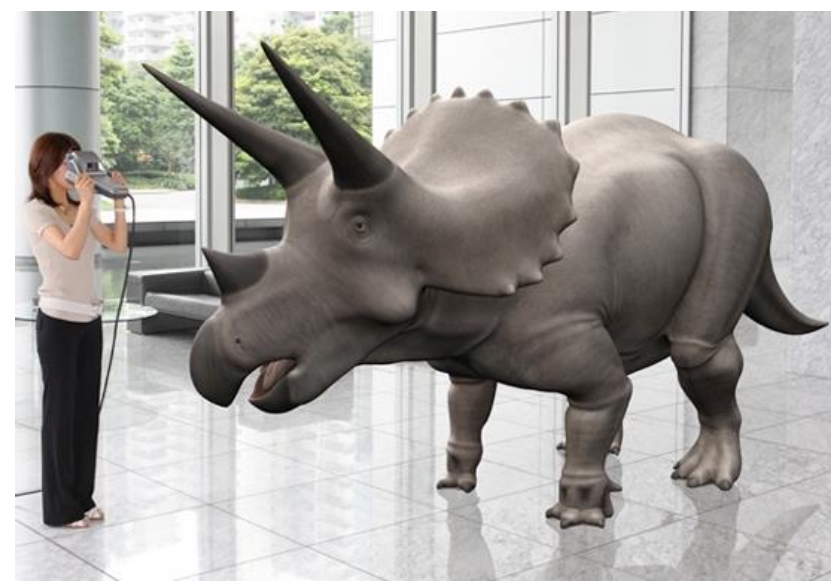

Gambar 1. Manfaat AR dalam bidang pendidikan

Pada bidang kesehatan merupakan salah satu bidang yang paling penting bagi sistem Augmented Reality. Contoh penggunaannya adalah pada pemeriksaan sebelum operasi, seperti CT Scan atau MRI yang memberikan gambaran kepada ahli bedah mengenai anatomi internal pasien. Dari gambar-gambar ini kemudian direncanakan. Augmented Reality dapat diaplikasikan sehingga tim bedah dapat melihat data CT Scan atau MRI pada pasien saat pembedahan berlangsung. Penggunaan lain adalah untuk pencitraan ultrasonik, dimana teknis ultrasonik dapat mengamati pencitraan fetus yang terletak di abdomen wanita yang hamil.

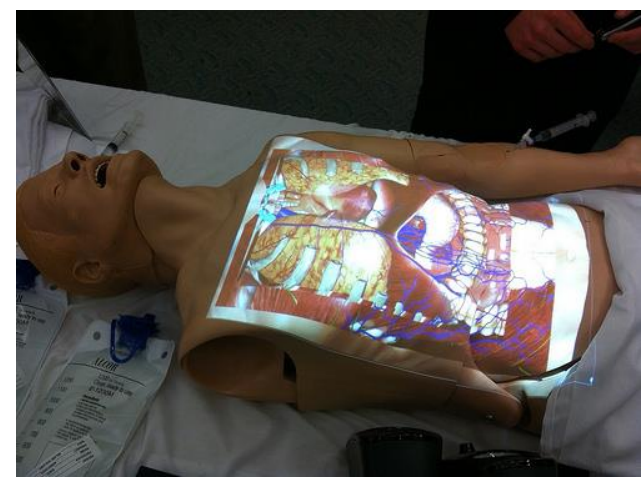

Gambar 2. Manfaat AR dalam bidang kesehatan

Marker adalah sebuah penanda yang didalamnya terdiri dari kumpulan titik acuan untuk memudahkan komputasi dari pengukuran parameter- parameter yang dibutuhkan dalam pembuatan Augmented Reality. Marker dapat berupa warna atau gambar, marker yang paling sederhana adalah marker matrix. Marker matrix menggunakan 2D barcode sederhana yang dipakai untuk mengenali sebuah objek dan untuk mengetahui hubungan antara posisi kamera dengan penanda tersebut. Ukuran standar marker adalah 631 x 634 pixel.

Marker berbentuk sebuah gambar berpola khusus dan sudah dikenali oleh Template Memory ARToolkit, marker berfungsi untuk dibaca dan dikenali oleh kamera lalu dicocokan dengan template ARToolkit, setelah itu kamera akan me-render objek 3D diatas marker. Marker standar yang sering dipakai adalah marker Hiro dan marker Kanji karena pola tersebut sudah ada pada template ARToolkit[3]. 


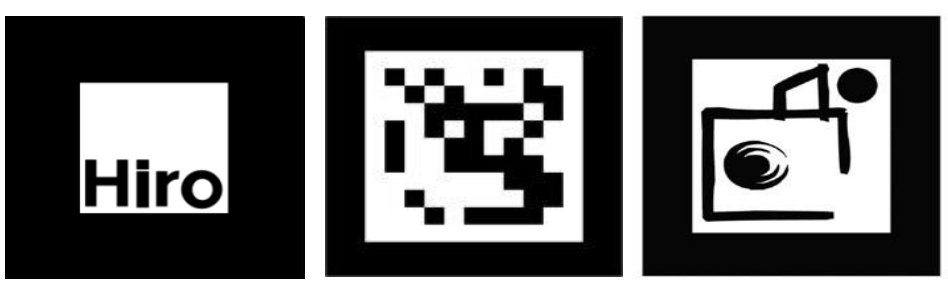

Gambar 3. Pola Marker

Kelebihan dari multimedia adalah menarik indra dan menarik minat, karena merupakan gabungan antara pandangan, suara, dan gerakkan. Lembaga riset dan penerbitan komputer yaitu Computer Teknology Research (CRT) menyatakan bahwa orang hanya mampu mengingat $20 \%$ dari yang dilihat dan 30\% dari yang didengar . tetapi orang mengingat 50\% dari yang dilihat dan yang didengar dan $80 \%$ dari yang dilihat, didengar, dan yang dilakukan secara langsung[4].

Pentingnya penggunaan multimedia menurut Suyanto[5] antara lain:

a. Membantu meratakan zaman informasi ke jutaan orang yang belum memakai komputer.

b. Menyampaikan informasi secara efektif, karena tidak hanya menampilkan teks semata tetapi juga menghidupkan teks dengan menyertakan bunyi, gambar, musik, animasi, dan video.

c. Mendorong keterlibatan dan penggalian lebih jauh atas aplikasi multimedia untuk pengajaran dan pendidikan dalam rangka meraih keunggulan bersaing perusahaan.

\section{METODE PENELITIAN}

Metode pengumpulan data dalam perancangan animasi sebagai media pembelajaran ini dilakukan sebagai penelitian awal, penulis menggunakan beberapa metode sebagai berikut :

1. Observasi atau pengamatan

Pengumpulan data penelitian ini akan dilakukan melalui pengamatan langsung terhadap obyek analisis untuk menggali aspek-aspek yang relevan dan penting sebagai dasar analisis dan interpretasi yang akan dilakukan.

2. Wawancara

Wawancara dimaksudkan untuk memperoleh data kualitatif serta beberapa keterangan atau informasi dari informan.

3. Dokumentasi

Penggunaan dokumen dalam penelitian ini adalah dokumen resmi dari jurusan tentang arsip ataupun dokumen, mencakup surat-surat, data-data, catatan, foto-foto kegiatan, dan lainnya yang relevan.

Pengembangan sistem informasi multimedia tidak akan berhasil dengan baik jika itdak melibatkan pemakai pengguna akhir, Menurut Raymond Mc Leod ada langkah khusus dalam mengembangkan sistem multimedia diantara lain[6] :

1. Mendefinisikan Masalah

Analisis sistem mengidentifikasikan kebutuhan pemakai dan menentukan bahwa pemecahanya memerlukan multimedia.

2. Merancang Konsep

Dilaksanakan dengan memilih karyawan, staf atau bekerjasama dengan profesional broadcasting seperti produser, sutradara, pemain, teknisi, video dll, terlibat dalam suatu rancangan konsep yang menentukan keseluruhan pesan.

3. Merancang Isi

Pada tahap ini adalah proses penegembangan dalam rancangan isi dengan menyiapkan spesifikasi aplikasi yang dipilih secara rinci. Pada saat inilah media yang akan digunakan dipilih. 
4. Menulis Naskah

Dialog,isi cerita dan semua elemen yang akan di informasikan disusun sedemikian rupa agar mudah dalam penyampaian

5. Merancang Grafik

Grafik yang dipilih yang mendukung dialog, seperti gambar-gambar yang akan digunakan pada latar belakang atau perlengkapan lain yang digunakan dalam pembuatan video.

6. Memproduksi Sistem

Pengembangan sistem memproduksi berbagai bagian yang menyatukan dengan sistem. Selain mengembangkan perangkat lunak dan aplikasi, tugasnya mencangkup kegiatan khusus seperti menyunting video, memasukan suara atau authoring adalah penggabungan elemen-elemen yang terpisah dengan menggunakan software khusus.

7. Melakukan Tes Pemakaian

Analisi sistem mendidik pemakaidalam penggunaan sistem dan memberikan kesempatan bagi pemakai untuk akrab dengan semua sistem yang digunakan.

8. Menggunakan Sistem

Setelah pemakai setuju dan puas dengan sistem yang dibuat, maka sistem tersebut segera di implementasikan.

9. Memelihara Sistem

Seperti sistem berbasis komputer lain, sistem multimedia harus dipelihara. Perbedaan utamanya adalah pemakai tidak dapat diharapkan untuk melaksanakan pemeliharaan. Ini adalah tugas spesialis dan profesional. Yang perlu diketahui adalah multimedia bukanlah enduser computing.

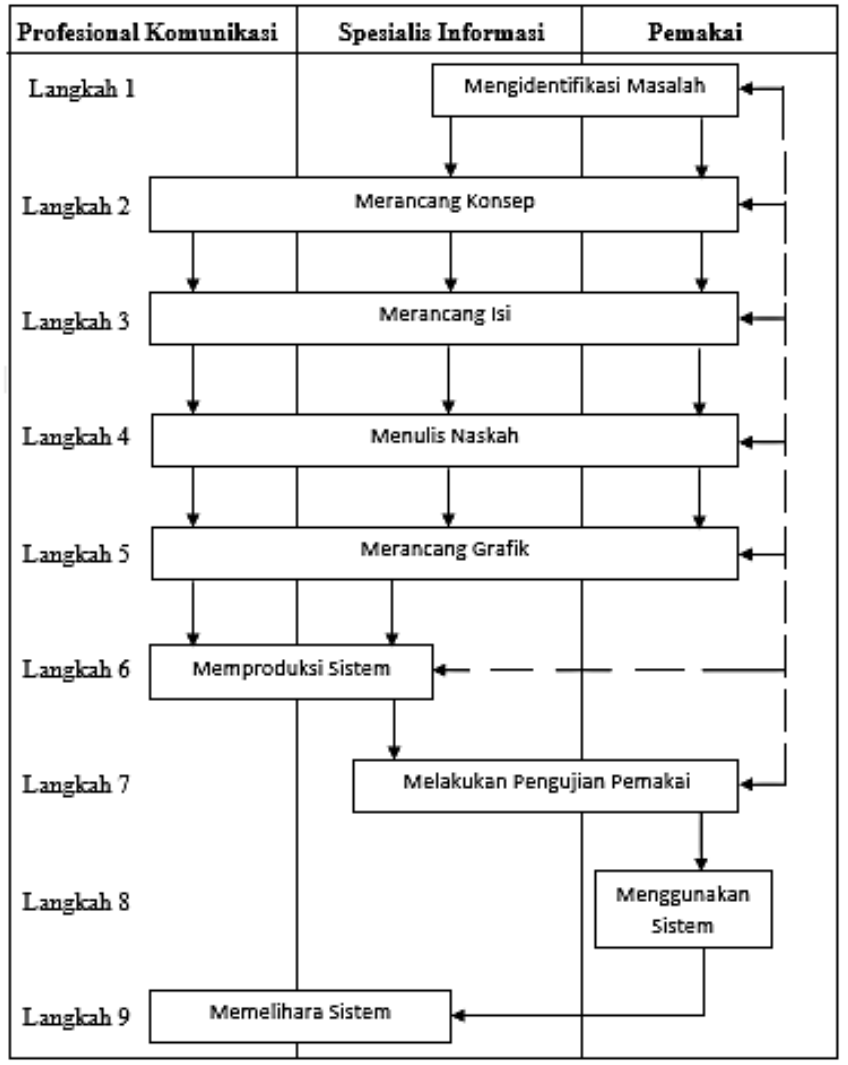

Gambar 4. Proses Pengembangan Sistem Multimedia

Keterangan:

$\longrightarrow:$ : Arah Data / Arus Data 
Sebelum membangun sebuah aplikasi Augmented Reality diperlukan beberapa hardware dan software untuk membuat program dan sistemnya. Karena program tidak akan berjalan jika ada salah satu hardware dan software yang diperlukan. Pada tahap ini akan diuraikan tentang perancangan sistem yang akan dibuat untuk terwujudnya penelitian yang diinginkan. Perancangan yang akan dibahas adalah perancangan menggunakan software, karena pada dasarnya hardware hanya digunakan sebagai media pendukung saja. Berikut adalah gambaran prinsip kerja Augmented Reality yang akan disampaikan dalam bentuk diagram[7].

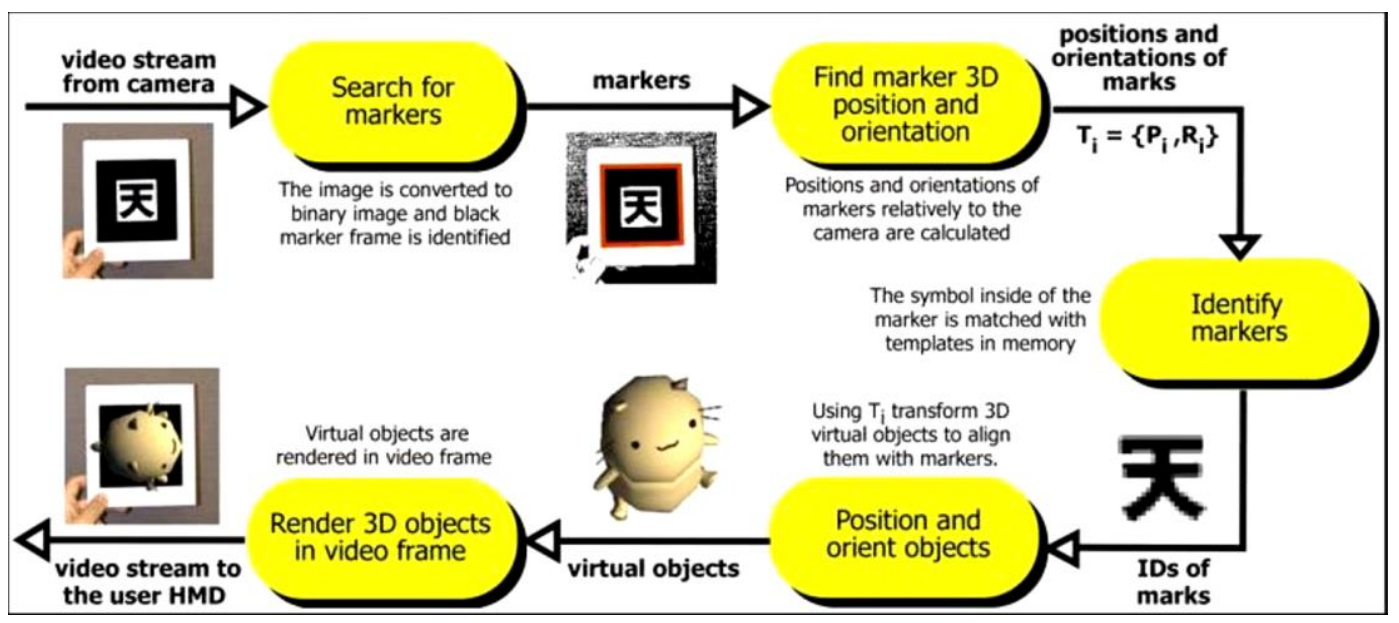

Gambar 5. Proses Kerja ARToolkit

1. Kamera menangkap gambar marker dari dunia nyata secara real time.

2. Perangkat lunak dalam komputer mencari marker pada masing-masing frame video.

3. Jika ditemukan sebuah garis tepi dari marker, maka digunakan perhitungan matematika untuk menghitung posisi kamera relatif terhadap kotak warna hitam.

4. Tiap kali posisi kamera diketahui maka model grafis hasil rekayasa komputer digambarkan pada posisi yang sama.

5. Model tersebut ditampilkan di atas gambar video dunia nyata dan tampak menempel pada marker yang berbentuk kotak.

6. Hasil akhir menunjukkan jika user melihat pada tampilan, maka akan tampak objek virtual tambahan pada dunia nyata.

\section{HASIL DAN PEMBAHASAN}

Kegiatan perancangan konsep meliputi pemilihan tema yaitu sistem dapat dijadikan objek presentasi atau penyampaian materi kepada anak-anak sehingga objek yang dibuat perlu memperhatikan pemilihan warna, bentuk, ukuran, penataan gambar dan materi yang menarik. Adapun perancangan konsep sistem adalah sebagai berikut.

Media edukasi yang akan dibuat memberikan informasi tentang bentuk gigi pada manusia dengan memanfaatkan buku cerita yang terdapat beberapa marker untuk meunculkan objek 3D. Adapun perencanaan isi dari buku cerita edukasi kesehatan gigi bagi anak adalah sebagai berikut. 


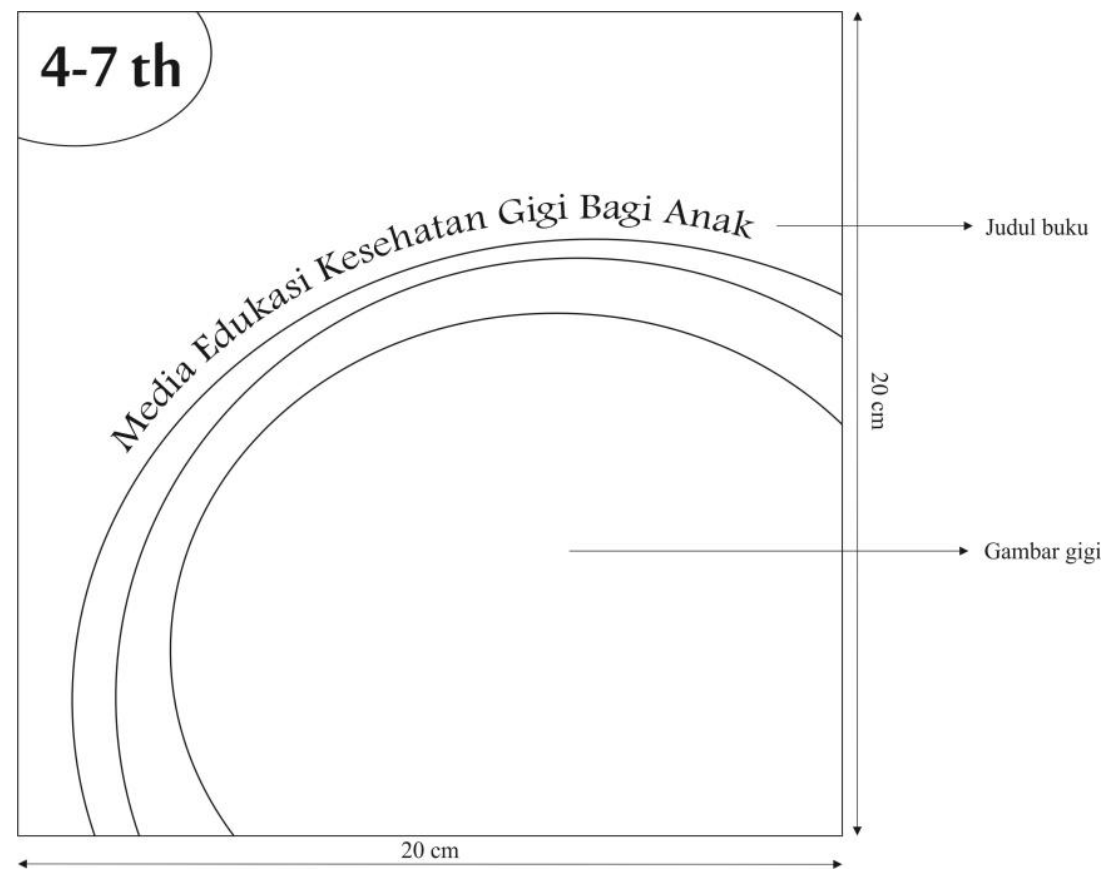

Gambar 6. Perancangan Cover Buku

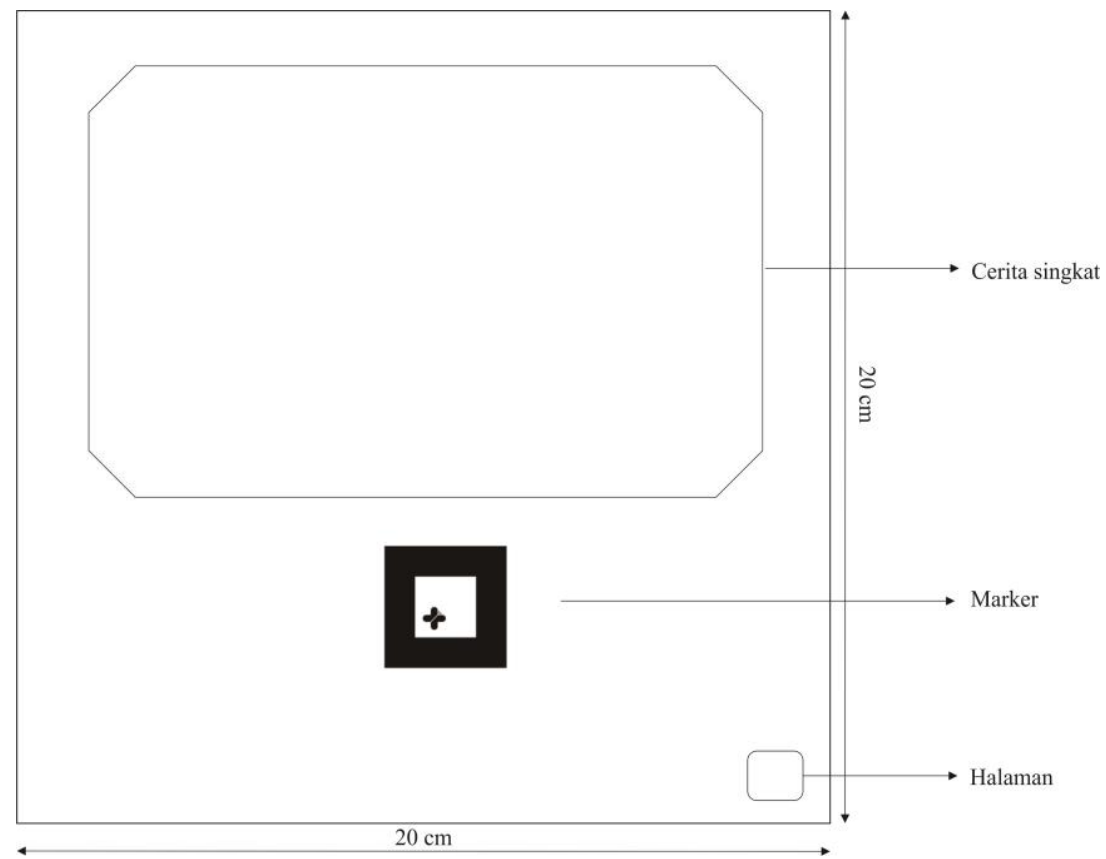

Gambar 7. Perancangan Halaman Isi Buku

Proses merancang grafik adalah menterjemahkan gambar 2 dimensi ke dalam bentuk 3 dimensi dengan menggunakan software 3DS Max. Sebagai langkah awal membuat bentuk-bentuk dasar dengan menggunakan panel create pada toolbar sebelah kanan, kemudian dilanjutkan dengan memodifikasi bentuk-bentuk tertentu yang dibutuhkan. Proses modifikasi terus dilakukan sampai bentuk objek menjadi yang diinginkan. 
Citec Journal, Vol. 2, No. 1, November 2014 - Januari 2015

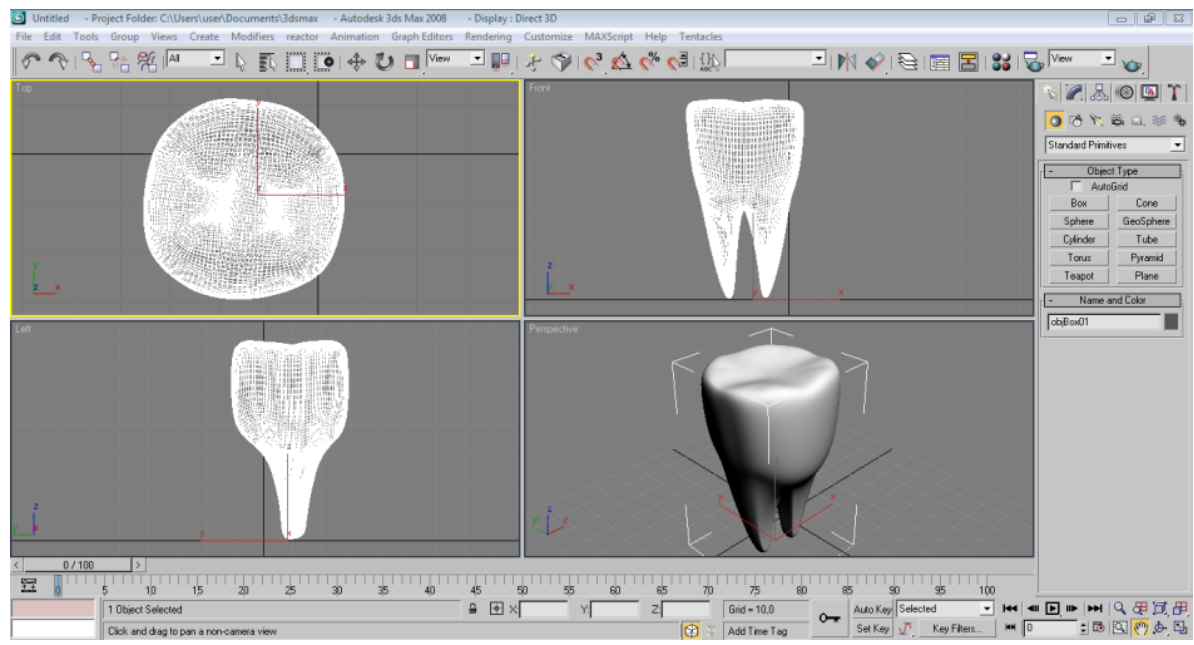

Gambar 8. Kegiatan Membuat Model Gigi Geraham

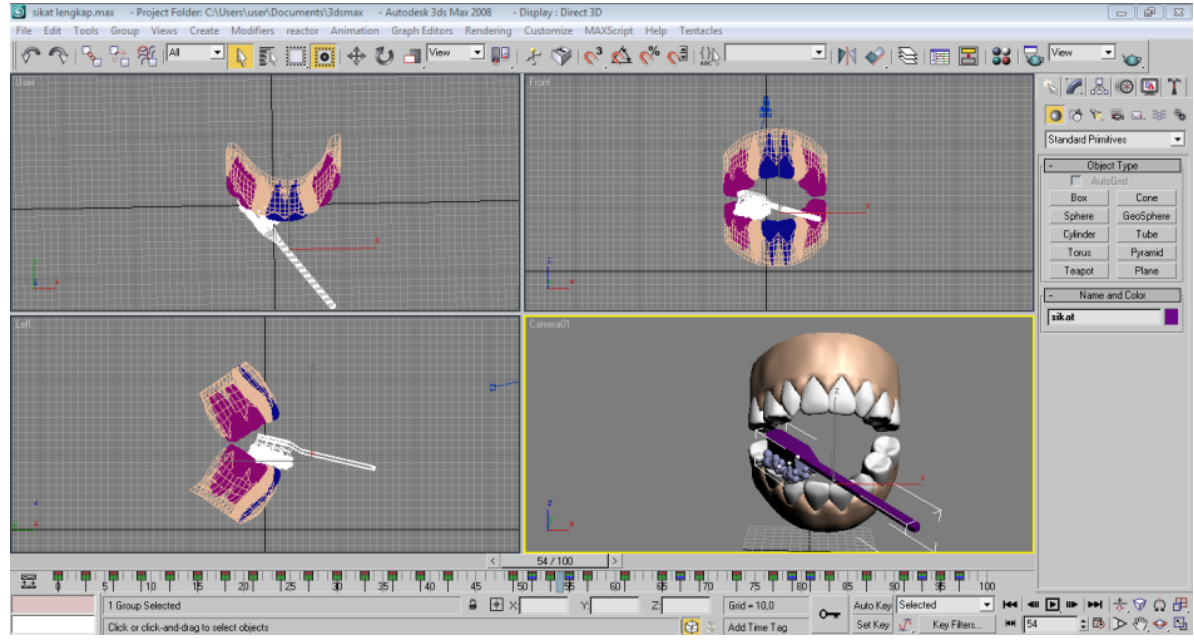

Gambar 9. Kegiatan Membuat Model Gosok Gigi

Setelah objek selesai dibangun maka selanjutnya adalah menyimpan atau mengekspor dalam bentuk VRML (*.WRL). Memproduksi sistem dengan membuat buku sebagai media penghubung antara Augmented Reality dengan marker. Berikut adalah gambar per halaman yang memuat rincian media yang dibuat. Buku ini dilengkapi dengan marker dan CD installer untuk menginstall ARToolKit sebagai pembaca marker tersebut. 


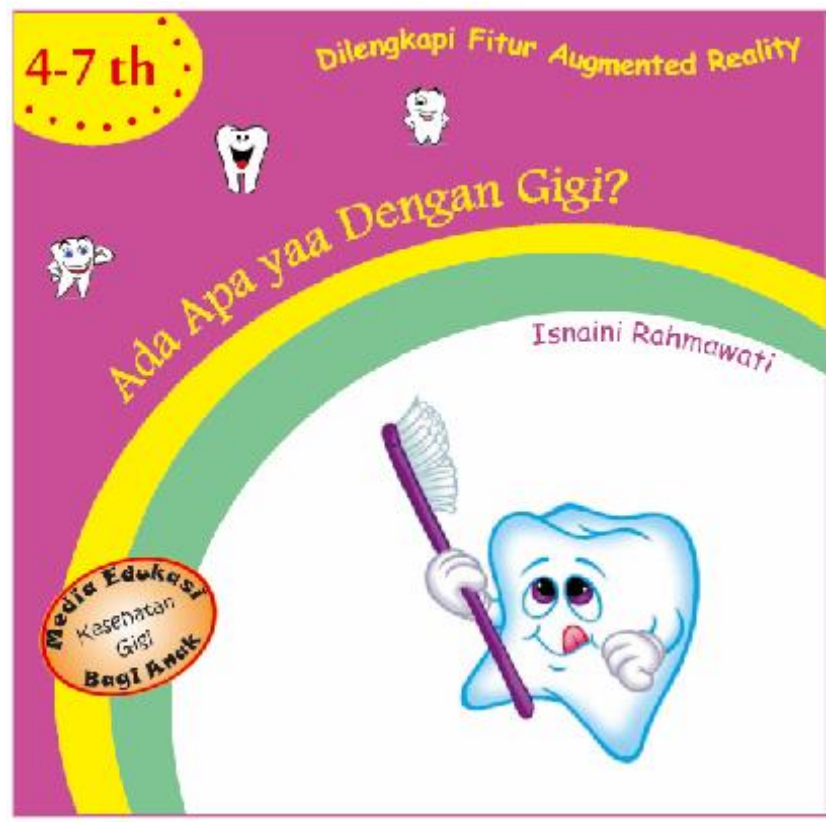

Gambar 10. Cover Buku

\section{Panduan buku berbasis Augmented Reality}

Buku ini dilengkapi fitur Augmented Reality sehingga dapat melihat objek secara virtual.

Untuk dapat menggunakan Augmented Reality

1. Install $C D$ pada komputer (yang memiliki kamera)

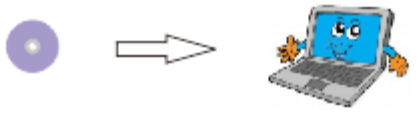

2. Arahkan Marker yang ada pada tiap halaman ke kamera

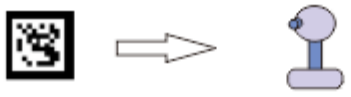

3. Objek 3D akan muncul pada monitor

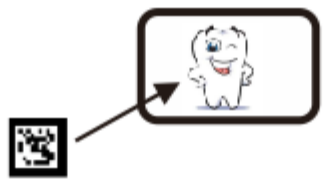

Gambar 11. Panduan Penggunaan Buku

Halaman panduan penggunaan buku menjelaskan bagaimana cara menggunakan Augmented Reality yang terdapat pada buku tersebut. Yang pertama menginstall ARToolKit yang terdapat pada CD yang disertakan. Setelah terinstall, aplikasi dapat segera digunakan dengan mengarahkan marker pada kamera komputer, maka secara otomatis marker akan terbaca dan objek 3D muncul pada monitor. 
Citec Journal, Vol. 2, No. 1, November 2014 - Januari 2015

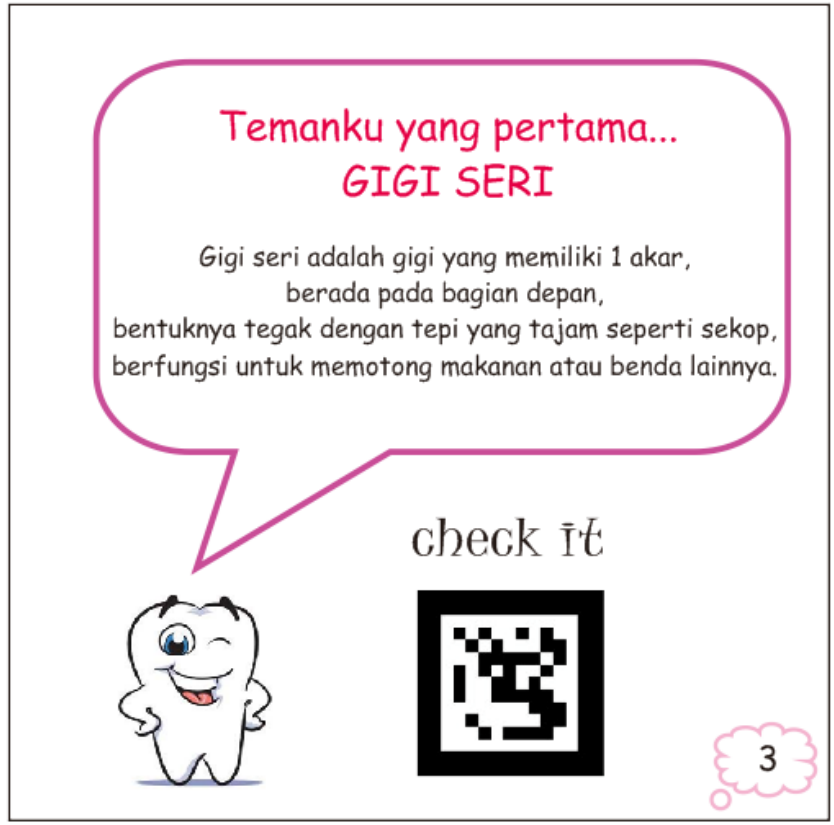

Gambar 12. Halaman Gigi Seri

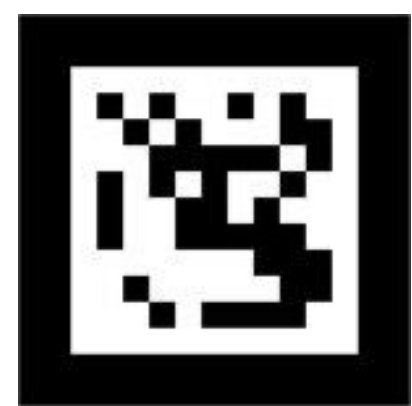

Gambar 13. Marker untuk Gigi Seri

Agar Marker yang sudah dibuat bisa dikenali oleh komputer saat tertangkap sebuah kamera, maka marker tersebut harus di recognized ke ARToolKit.

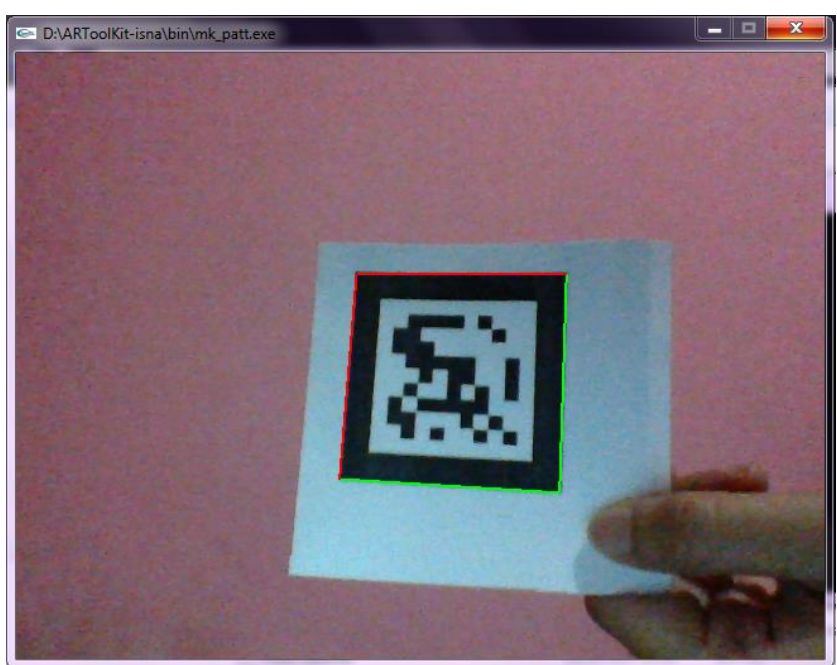

Gambar 14. Mendeteksi Marker 
Untuk Memastikan marker sudah dideteksi oleh aplikasi maka dilakukan pengetesan dan pengecekan, jika gambar 3d sudah muncul di layar komputer setelah kamera menangkap gambar marker berarti sudah berhasil dilakukan.

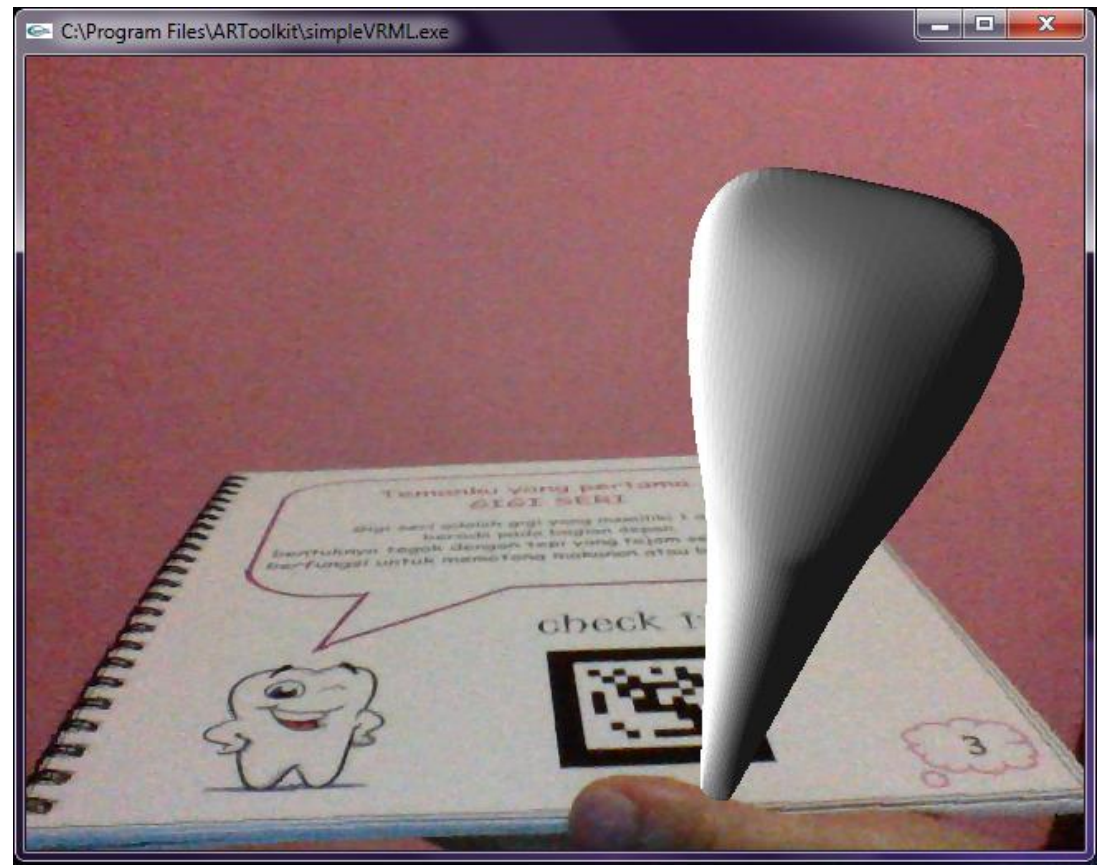

Gambar 15. Hasil Pengujian Marker

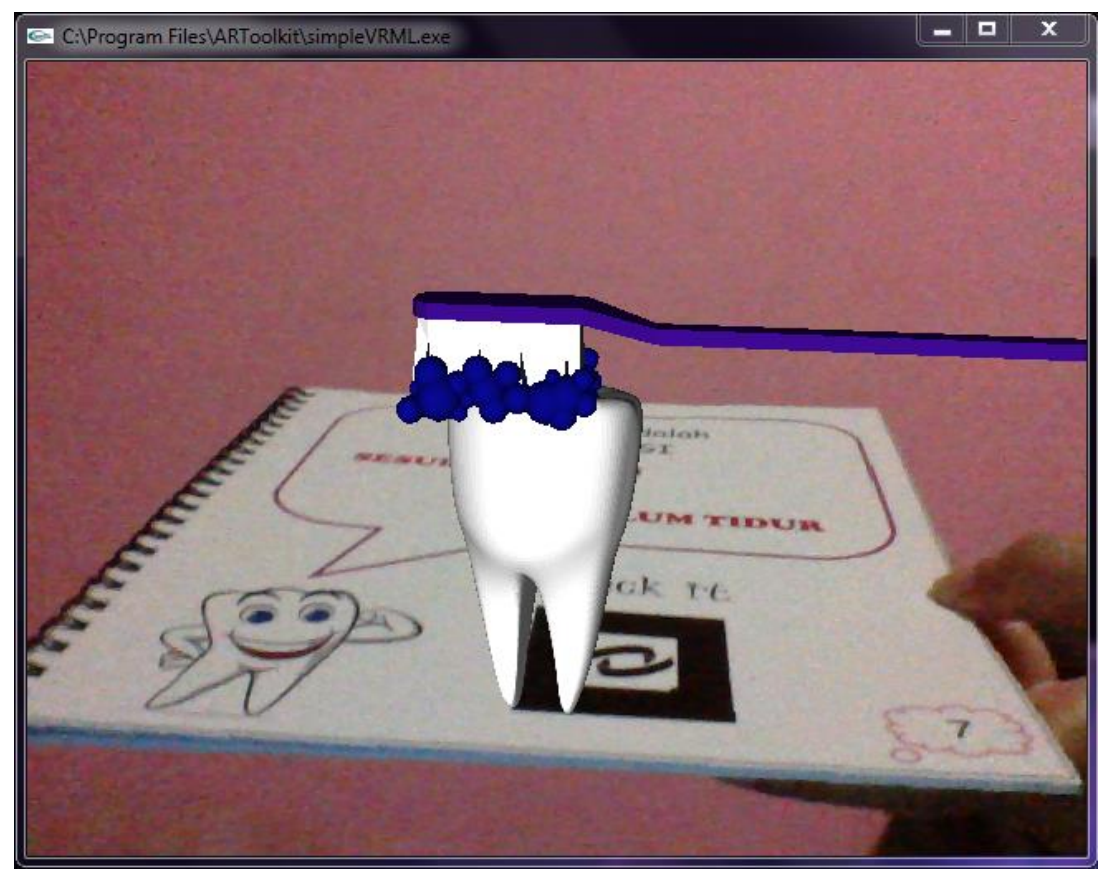

Gambar 16. Pengujian Marker dengan Objek Animasi 3D

Setelah tahap mengetes sistem dan aplikasi layak maka sistem dapat digunakan. Hal ini dapat memungkinkan proses peninjauan kembali tingkat efektifitas sistem ini. Dengan melihat kembali tahap-tahap perancangan yang sudah dijelaskan pada bab sebelumnya.

Aplikasi ini juga diujicobakan untuk mempermudah penyampaian materi tentang kesehatan gigi bagi anak. Digunakan untuk anak berusia 4-8 tahun dalam hal ini siswa Pendidikan 
Citec Journal, Vol. 2, No. 1, November 2014 - Januari 2015

ISSN: 2354-5771

Anak Usia Dini (PAUD) sampai Sekolah Dasar (SD) kelas 2. Pengajar yang menggunakan akan lebih mudah dalam menarik perhatian anak. Sekaligus memperkenalkan teknologi Augmented Reality kepada masyarakat khususnya anak-anak.

Selain digunakan di Pendidikan Anak Usia Dini (PAUD) dan Sekolah Dasar (SD), sistem ini juga dapat digunakan secara pribadi dalam rumah tangga. Setelah menginstall CD ARToolKit pada komputer maka marker pada buku dapat terbaca. Sehingga mempermudah pengguna untuk mengimplementasikan aplikasi tersebut.

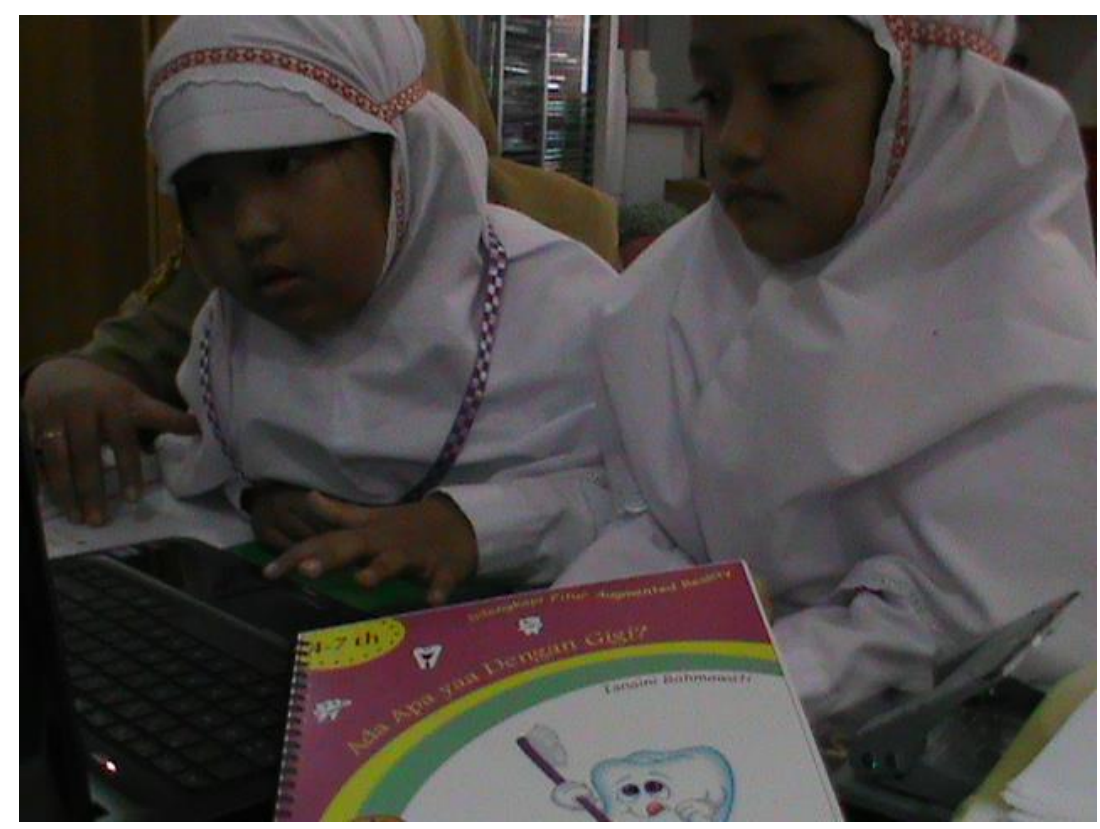

Gambar 17. Kegiatan Implementasi di TK

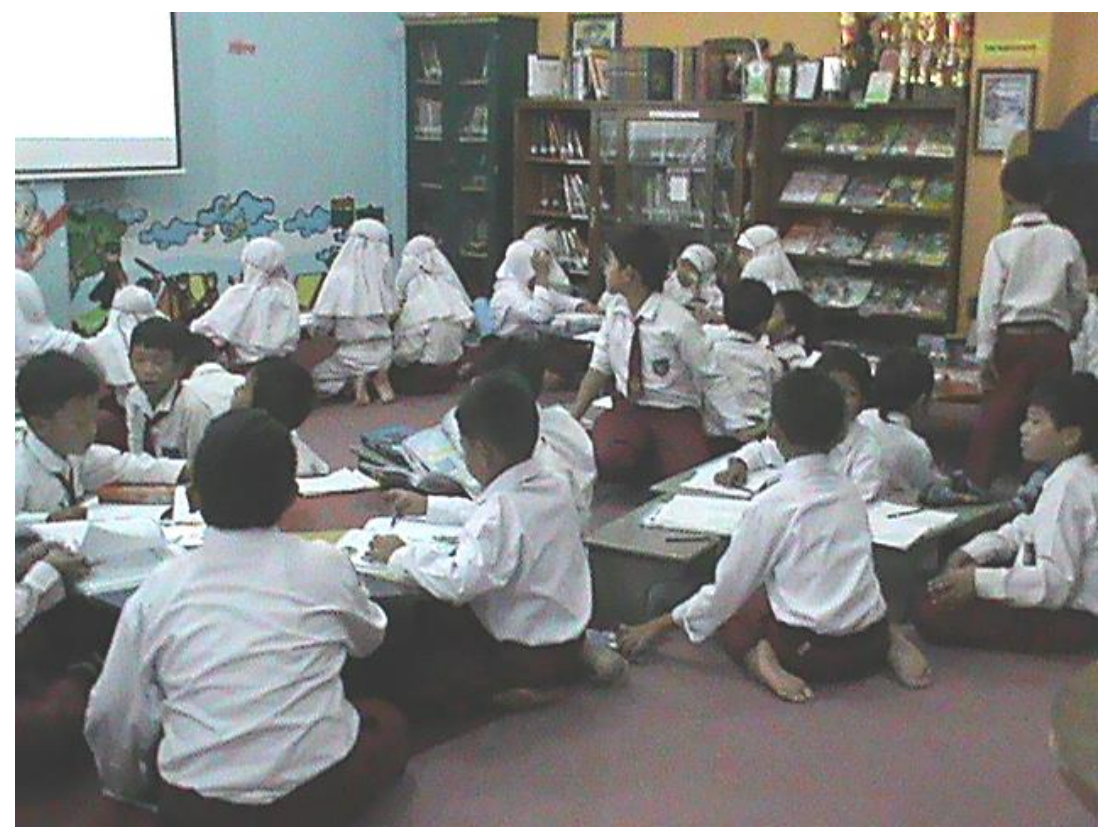

Gambar 18. Kegiatan Implementasi di SD 
Penelitian ini menggunakan metode eksperimental semu (Quasy Eksperiment) dengan rancangan penelitian One Group Pretest- Postest. Rancangan penelitian ini bertujuan untuk mengetahui apakah ada pengaruh terhadapa penggunaan teknologi AR sebagai media edukasi kesehatan gigi pada anak.

Tabel 1. Karakteristik Anak Menurut Jenis Kelamin

\begin{tabular}{lcccc}
\hline \multirow{2}{*}{$\begin{array}{c}\text { Jenis } \\
\text { Kelamin }\end{array}$} & $\begin{array}{c}\text { Perlakuan I } \\
\text { (Media AR) }\end{array}$ & $\begin{array}{c}\text { Perlakuan II } \\
\text { (Ceramah) }\end{array}$ & $\begin{array}{c}\text { Perlakuan I } \\
\text { (Media AR) }\end{array}$ & $\begin{array}{c}\text { Perlakuan II } \\
\text { (Ceramah) }\end{array}$ \\
\hline Laki-laki & 18 & 17 & $60 \%$ & $56,67 \%$ \\
Perempuan & 12 & 13 & $40 \%$ & $43,33 \%$ \\
\hline Jumlah & 30 & 30 & $100 \%$ & $100 \%$ \\
\hline
\end{tabular}

Berdasarkan hasil penelitian pada table 1 diatas memperlihatkan bahwa jumlah responden pada kelompok perlakuan dengan metode AR, laki-laki 18 (60\%) dan perempuan 12 (40\%), sedangkan kelompok perlakuan dengan metode Ceramah, laki-laki $17(56,67 \%)$ dan perempuan $13(43,33 \%)$.

Tabel 2.Karakteristik Anak Menurut Umur

\begin{tabular}{ccccc}
\hline \multirow{2}{*}{ Jenis } & \multicolumn{2}{c}{ Jumlah } & \multicolumn{2}{c}{ Persentase } \\
\cline { 2 - 5 } & Perlakuan I & Perlakuan II & Perlakuan I & Perlakuan II \\
& (Media AR) & (Ceramah) & (Media AR) & (Ceramah) \\
\hline 7 tahun & 12 & 10 & $40 \%$ & $33,33 \%$ \\
8 tahun & 18 & 20 & $60 \%$ & $66,67 \%$ \\
\hline Jumlah & 30 & 30 & $100 \%$ & $100 \%$ \\
\hline
\end{tabular}

Berdasarkan Tabel 2 memperlihatkan bahwa umur responden kelompok perlakuan dengan metode AR, 7 tahun berjumlah 12 (40\%) dan 8 tahun berjumlah 18 (60\%), kelompok perlakuan dengan metode Ceramah, 7 tahun berjumlah $10(33,33 \%)$ dan 8 tahun berjumlah 20 $(66,67 \%)$.

Tabel 3. Hasil Analisis Pembelajaran Menggunakan Media AR

\begin{tabular}{ccccc}
\hline \multirow{2}{*}{$\begin{array}{c}\text { Tingkat } \\
\text { Pengetahuan }\end{array}$} & \multicolumn{5}{c}{ Sumber Data } \\
\cline { 2 - 5 } & Pre test & $\%$ & Post test & $\%$ \\
\hline Buruk & 14 & 46,67 & - & - \\
Kurang & 16 & 53,33 & - & - \\
Cukup & - & - & 3 & 10 \\
Baik & - & - & 27 & 90 \\
\hline
\end{tabular}

Berdasarkan tabel 3 dapat dilihat peningkatan pengetahuan responden. Bahwa 13 responden $(92,86 \%)$ mengalami peningkatan pengetahuan dari buruk menjadi baik, 1 responden $(7,14 \%)$ mengalami peningkatan pengetahuan buruk menjadi cukup, 14 responden $(87,5 \%$ )mengalami peningkatan pengetahuan kurang menjadi baik, dan 2 responden $(12,5 \%)$ mengalami peningkatan pengetahuan kurang menjadi cukup. 
Citec Journal, Vol. 2, No. 1, November 2014 - Januari 2015

Tabel 4. Hasil Analisis Pembelajaran Metode Ceramah

\begin{tabular}{lcccc}
\hline Tingkat Pengetahuan & \multicolumn{5}{c}{ Sumber Data } \\
\cline { 2 - 5 } & Pre test & $\%$ & Post test & $\%$ \\
\hline Buruk & 16 & 53,33 & - & - \\
Kurang & 14 & 46,67 & - & - \\
Cukup & - & - & 14 & 46,67 \\
Baik & - & - & 16 & 53,33 \\
\hline
\end{tabular}

Berdasarkan tabel 4 dapat diketahui peningkatan pengetahuan responden. Bahwa 6 responden $(37,5 \%)$ mengalami peningkatan pengetahuan dari buruk menjadi baik, $10(62,5 \%)$ responden mengalami peningkatan pengetahuan buruk menjadi cukup, 10 responden $(71,43 \%)$ mengalami peningkatan pengetahuan kurang menjadi baik, dan 4 responden $(28,57 \%)$ mengalami peningkatan pengetahuan kurang menjadi cukup.

Tabel 5. Rerata Nilai Pembelajaran Pretest dan Posttest pada Metode Ceramah dan Metode Media AR

\begin{tabular}{cccccc}
\hline \multirow{2}{*}{ Kelompok } & \multicolumn{2}{c}{ Rerata } & \multicolumn{2}{c}{ Uji Statistik } & \multirow{2}{*}{ Keterangan } \\
\cline { 2 - 5 } & Pretest & Postest & t & P & \\
\hline Media AR & 7,60 & 17,17 & $-23,567$ & 0,0001 & Bermakna \\
Ceramah & 7,20 & 15,67 & $-15,327$ & 0,0001 & Bermakna \\
\hline
\end{tabular}

Berdasarkan tabel 5 dapat diketahui bahwa terdapat perubahan mean tingkat pengetahuan tentang kesehatan gigi. Mean pre test metode AR sebesar 7,60 sedangkan mean post test sebesar 17,17 dan mean metode Ceramah sebesar 7,20 sedangkan mean post test sebesar 15,67. Dilihat dari nilai $\mathrm{p}=0,0001<0,05$ dapat disimpulalkan adanya pengaruh pendidikan kesehatan gigi dalam meningkatkan pengetahuan tentang kesehatan gigi anak.

Tabel 6. Hasil Analisis Perbedaan Pengaruh Pendidikan Kesehatan Gigi Menggunakan Metode Ceramah Dan Menggunakan Media AR.

\begin{tabular}{cccccc}
\hline Kelompok & Mean & $\begin{array}{c}\text { Standar } \\
\text { Deviasi }\end{array}$ & $\mathrm{t}$ & $\mathrm{p}$ & Keterangan \\
\hline Media AR & 17,17 & 1,555 & 3,254 & 0,002 & Bermakna \\
Ceramah & 15,67 & 1,988 & 3,254 & 0,002 & Bermakna \\
\hline
\end{tabular}

Berdasarkan tabel 4.10 nilai rata-rata (mean) sesudah perlakuan menggunakan metode AR dengan lembar hasil balik sebesar 17,17 dan nilai rata-rata (mean) sesudah perlakuan menggunakan metode demonstrasi dengan alat peraga gigi sebesar 15,67, yang berarti mean differentnya sebesar 1,500 . Bila dilihat dari probabilitas $=0,002$, maka $p=0,002 \leq 0,005$ yang berarti ada perbedaan pengaruh pendidikan kesehatan gigi menggunakan metode AR dengan metode Ceramah dalam meningkatkan pengetahuan anak. 


\section{KESIMPULAN}

Dari penjelasan dan penguraian pada pembahasan sebelumnya dan sampai akhir dari perancangan aplikasi, maka dapat disimpulkan bahwa:

1. Aplikasi tidak mengalami kendala dalam implementasi dan dapat digunakan secara mandiri.

2. Teknologi AR bisa menjadi alternatif penyampaian materi kepada peserta didik.

3. Dari Hasil pengujian anak-anak lebih tertarik dan antusias melihat sebuah visual yang dikemas dengan teknologi informasi maupun animasi.

4. Apliaksi ini bisa digunakan memperluas wawasan masyarakat umun tentang teknologi informasi terutama tentang Augmented Reality.

\section{SARAN}

Penulis menyadari dalam pembuatan Aplikasi AR ini masih terdapat banyak kekurangan yang dapat diperbaiki, maupun dilengkapi oleh pengembang selanjutnya. Maka penulis menyarankan kepada pembaca dan seluruh pihak yang ingin membuat Virtual Galeri yang mirip dengan ini agar dapat memperbaiki dan memperhatikan kekurangan yang ada sebagai berikut:

1. Menambah objek 3 dimensi yang berhubungan dengan kesehatan gigi ke dalam buku sehingga buku media edukasi ini memuat lebih banyak informasi.

2. Memperbaiki kualitas marker sehingga dapat dibaca dalam berbagai kondisi dan tidak bermasalah dengan cahaya ataupun pergerakan.

3. Untuk merancang aplikasi ini harus memperhatikan dalam mengekspor objek 3D ke bentuk Augmented Reality, beberapa objek menjadi tidak seperti yang diinginkan, maka diperlukan teori yang lebih mendalam untuk dapat membentuk objek 3D agar terlihat lebih indah.

4. Aplikasi yang penyusun buat belum sempurna, untuk itu diharapkan nantinya dapat diberikan tambahan fitur - fitur yang lebih baik sehingga dapat lebih bermanfaat lagi.

\section{DAFTAR PUSTAKA}

[1] Rochmah, S. N., Widayati, S., Miah, M., 2009, Biologi: SMA dan MA Kelas XI, Pusat Perbukuan, Departemen Pendidikan Nasional, Jakarta.

[2] Kim, S., 2010, u-Traditional Market Model Based on 5W1H Context Aware Technology, International Conference, Parallel and Distributed Computing and Network, Chongqing China, 13-14 Desember 2010.

[3] Andriyadi, A., 2009, Augmented Reality with ARToolkit: Reality Leaves a Lot to Imagine, ARTeam, Bandar Lampung.

[4] Munir, 2012, Multimedia Konsep Dan Aplikasi Dalam Pendidikan, Alfabeta, Bandung.

[5] Suyanto, M., 2003, Multimedia Alat Untuk Meningkatkan Keunggulan Bersaing, Andi Offset, Yogyakarta.

[6] Hidayat, T., Rahmawati, I., 2014, Desain dan Implementasi Teknologi Augmented Reality sebagai Media Edukasi Kesehatan Anak. Seminar Nasional Teknologi Informasi dan Mulimedia, Yogyakarta, 8 Februari 2014.

[7] Raymond, M., 1996, Sistem Informasi Manajemen: Studi Berbasis Komputer, Edisi Indonesia, Jilid II, Prenhallindo, Jakarta.

[8] Andriyadi, A., 2010. Tutorial Augmented Reality V.1.1, ARTeam, Bandar Lampung. 